\title{
Winter energy consumption in reading space of green library in cold regions
}

\author{
Jiwei $\mathrm{Li}^{1 *}$, Qiong Guan², Hui Yang ${ }^{2}$ \\ ${ }^{1}$ College of Civil Engineering and Architecture, Hebei University, Baoding 071002, China \\ ${ }^{2}$ Hebei Agricultural University, Baoding, 071001, China
}

Corresponding Author Email:47887840@qq.com

https://doi.org/10.18280/ijht.360413

Received: 3 April 2018

Accepted: 20 September 2018

Keywords:
libraries, green building, natural
lighting, solar energy, energy
consumption

\begin{abstract}
In recent years, green libraries are springing up in many Chinese universities. The green library is an energy-efficient type of library that provides an excellent reading environment. The library's energy efficiency relies on the careful design of natural and artificial lighting, illumination uniformity as well as heating efficiency. Therefore, this paper attempts to laid down an energy-efficient design to make the Hebei Agricultural University Library a green library. Specifically, the comprehensive energy consumption of the reading space was evaluated through dynamic and static simulations of illumination variation, illumination uniformity, daylighting factor and supplementary lighting under different windowing conditions. The evaluation results were coupled with the enclosure energy consumption to determine the optimal energy consumption plan. From this case study, it is found that the window area in the south-facing reading space is beneficial to the energy efficiency of the whole library. Thus, the south-facing window area should be increased as much as possible.
\end{abstract}

\section{INTRODUCTION}

A library is an important carrier of the progress of human civilization. With the progress of society, the quantity and scale of libraries have been greatly developed. The enrollment size of China institutions of higher learning is expanding and by the end of 2016, the total number of Chinese institutions of higher learning is 2,284. In order to meet the increasing demand, university libraries have also begun to develop rapidly.

Under this background, a green library emerges as the times require, and so-called green library refers to the library building that meets the requirements of green building, namely energy-saving, water-saving, land-saving, and environmentfriendly library building [1].

The main functions of libraries are for books collection and reading. The requirement for daylighting and lighting is high, which needs to be considered comprehensively with the energy consumption of heating, air conditioning and so on. In the existing design work, designers often seldom consider the demand of lighting energy consumption, but only consider heating or air conditioning energy consumption. For other types of architectural design, this method has little influence on the overall energy consumption of the buildings, but the energy consumption of library lighting can account for $20-30 \%$ of the total energy consumption [2]. Considering the special demand of green libraries, if natural lighting and lighting are not considered comprehensively, there will be a serious impact on the final energy consumption, which will affect the green degree of the library.

\section{DAYLIGHTING REQUIREMENT OF THE READING SPACE OF THE LIBRARY}

The lighting of the library should give priority to natural daylighting [3], and in the room of natural daylighting, indoor daylighting can differ with outdoor weather circumstance, and the lighting time of natural light changes with period of a year [4]. Therefore, in the daylighting design, it's necessary to first analyze the local light climate situation and daylighting indicators. The main daylighting indexes of reading space include illumination, indoor daylighting uniformity and daylighting factor [5]. These lighting indexes are closely related to the daylighting of reading space.

Illumination refers to the luminous flux per unit area falling on the working surface, and the unit is Lx. In the study, it specifically refers to indoor illumination [6]. This index is commonly used, and it is easy to measure, intuitive, and objective. The illumination requirement in the design standard of building daylighting often puts forward different requirements according to the difference of working precision in the space, and the illumination of library should be $300 \mathrm{Lx}$ generally.

Daylight factor can quantify the indoor lighting effect by comparing the indoor illumination with the outdoor environment illumination, and indicates the percentage relationship between the natural illumination at a certain point in the room and the outdoor illumination [7]. For the reading room in a library, the better daylighting factor is between $5 \%$ $\sim 10 \%$. The amount of time that the building can use natural light is related to the geographical location of the city and the date of calculation [8]. Figure 1 shows a curve of daylighting hours per day. It can be seen from the figure that the daylighting hours are about 10 hours in winter and 14-15 hours in summer, which is related to the earth revolution law. The 
specific total lighting hours of different dates can be calculated according to $\mathrm{Eq}(1)$.

$T_{\text {day }}=-2.8 \times \cos (1.05 \times \mathrm{n})+12.27$

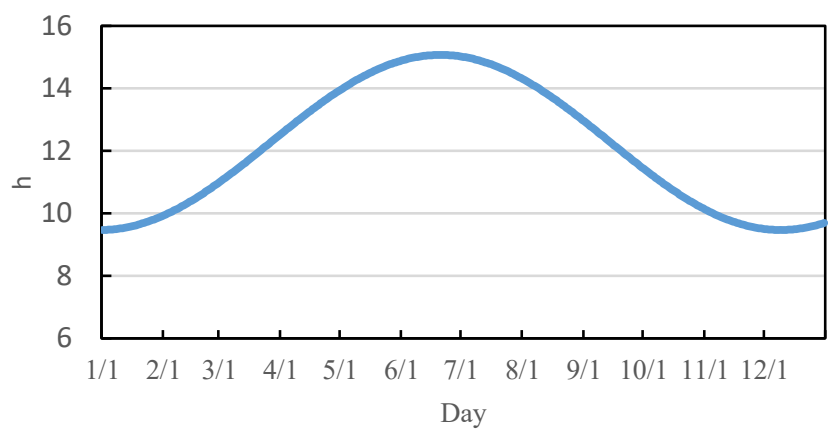

Figure 1. Curve of daylighting hours per day in Baoding

The uniformity of daylighting is the ratio of the lowest value to the average value of the daylighting factor on the assumed working surface [9]. The uniform distribution of indoor daylighting may make human eyes fatigue, reduce visual efficacy and lower work efficiency. The daylighting uniformity in working rooms of public buildings is not less than 0.7 according to the Standard for Lighting Design of Buildings. It is difficult of natural lighting to achieve the uniformity. In the design stage, it is necessary to ensure the daylighting uniformity through simulation analysis.

\section{ENERGY COMPOSITION OF READING SPACE OF LIBRARIES IN WINTER IN COLD REGIONS}

The energy consumption of library buildings mainly includes the energy consumption of lighting, heating, and some electronic equipment. Among these factors, lighting and heating should be mainly controlled in the design stage of buildings [10]. The energy consumption of lighting and heating is related to the composition of exterior enclosure. The exterior enclosure of buildings is mainly divided into walls and windows. Generally, the heat transfer coefficient of windows is larger and that of walls is smaller. The energy consumption of heating is smaller as the area of windows is smaller. But in the reading space, considering that the larger the window area is, the better the daylighting effect is, this law may be no longer applicable. In addition, if the reading room is on the south side of the building, the windows can also obtain solar energy and provide a certain amount of heat for the room. Therefore, it is necessary to deeply study the comprehensive energy consumption composition of the reading space.

\subsection{Lighting energy consumption}

The general building area of a modern library is relatively large, with longer opening time, and the design illumination of library lighting system is relatively stronger. In order to meet the needs of readers, the lighting system often runs 14 hours a day from morning till night. The formula for calculating the lighting energy consumption $\mathrm{E}_{\mathrm{L}}$ is as follows $\mathrm{Eq}(2)$ :

$E_{L}=P L D \times S$

\subsection{Heating consumption in winter enclosure structure}

Because of the temperature difference between indoor and outdoor in winter, the heating energy of enclosure structure will be removed from indoor to outdoor. The enclosure structure includes walls and doors and windows, and the insulation performance of walls is better than that of doors and windows. Especially in winter, the heat loss through exterior windows is very greater, so improving the thermal performance of exterior windows is important for building energy saving [12]. The heating consumption formula of the enclosure structure is as $\mathrm{Eq}(3)$ :

$$
\mathrm{E}_{\mathrm{h}}=\left(t_{i}-t_{e}\right)\left(\sum_{i=1}^{m} \varepsilon_{i} \times K_{i} \times F_{i}\right) / A_{0}
$$

\subsection{Energy directly benefited from solar energy}

The climate environment outside the building is the external disturbance, mainly including air temperature and humidity, wind speed and direction, solar radiation intensity, etc. The external disturbance exchanges heat with the indoor environment by means of thermal convection or thermal radiation through the enclosure structure. Among external disturbance factors, the solar radiation is the most influence factor, and the solar radiation intensity on each vertical plane is also different as the architectural orientation is different. Figure 2 shows the south solar radiation intensity in Baoding area. From the figure, it can be seen that the south solar radiation intensity is lower in summer and higher in winter, which is very beneficial to the solar energy utilization from the south window in winter.

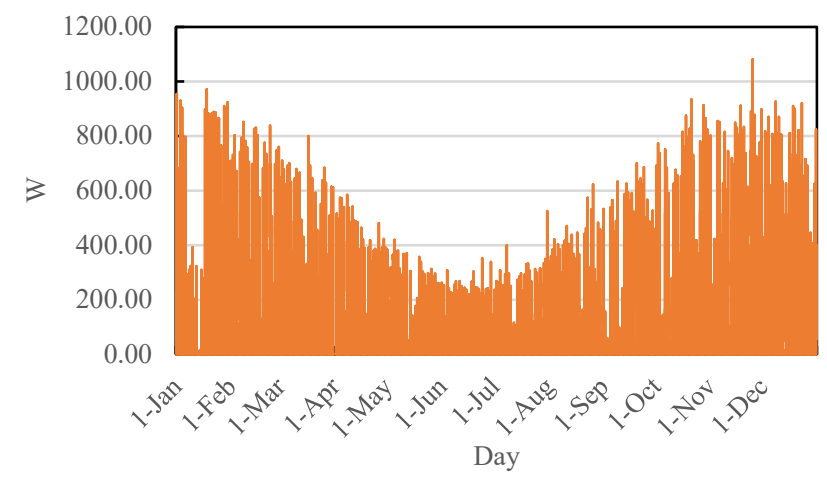

Figure 2. Hourly south solar radiation intensity in Baoding

Shading coefficient (SC) is used to indicate the influence of solar radiation on the interior and is the ratio of solar heat gained through translucent components (including translucent materials and shading facilities) under the reverse intake condition to solar heat gained through standard components under the same intake condition. The smaller the SC value is, the stronger the ability of the outer window to withstand solar radiation is. This is beneficial to reducing the cooling load in summer but not conducive to heating in winter. The calculation formula of the direct solar index $E_{S}$ of energy benefited from solar energy is as $\mathrm{Eq}(4)$ [13]:

$E_{S}=I \times S_{c} \times \alpha$ 
Building is a complex system, in which all factors influence each other. It is difficult to judge the design from a few simple numbers, and the form of combining different building element s will cause huge differences in energy consumption. If the architect does not have a quantitative grasp of the dynamic energy consumption from the beginning of the design, it's hard to discuss the optimization design. Therefore, it is necessary to use dynamic energy consumption simulation technology to carry out detailed energy consumption simulation prediction and comparison in terms of plans in different design stages, so as to truly understand the characteristics and changes in energy consumption of buildings for building energy-saving design.

\section{CALCULATION METHOD OF COMPREHENSIVE ENERGY}

\subsection{Consumption in library daylighting design daylighting design requirements for the reading space of the library}

The task of daylighting design is to create good lighting conditions to meet the requirements of indoor visual work. The key is to select and design the form, position and area of the light collecting opening correctly according to the requirements of visual work characteristics, so as to obtain good daylighting in the room and thus ensure the smooth implementation of visual work. This needs to focus on the following problems in the lighting design: appropriate illumination, lighting uniformity, reasonable light reflection ratio, glare prevention and auxiliary lighting minimization. For the reading space, the natural illumination shall reach $3001 x$, and the daylighting factor shall not be lower than $2 \%$. When the natural lighting cannot meet the requirements, artificial lighting shall be supplemented, and the illumination value shall not be lower than 3001x.

\subsection{Calculation method of energy consumption in reading space of the library}

The general calculation methods of space energy consumption include static estimation method and dynamic simulation method. The static estimation method: The heat consumption of each month in the coming heating period or heating period is assumed to be a stable heat transfer state, without considering the heat storage effect of each part of the enclosure structure. The method is simple and convenient for designers to manually calculate with the disadvantage of the inaccurate result. The dynamic simulation method takes into account all factors affecting building energy consumption. By simulating building energy consumption hour by hour and area by area, it can obtain the annual energy consumption variation hour by hour. The calculation result is more intuitive and accurate, but the operation is more complicated due to the more input parameters.

Both dynamic simulation method and static estimation method are considered in this study. By dynamically simulating the daylighting state of the reading space in the library, the study can obtain lighting energy consumption in an accurate manner, and by static estimation, it can determine the heating energy consumption of the reading space. The energy characteristics of the reading space can be obtained by coupling the two.
4.3 Calculation steps of energy consumption in the reading space of a library

\subsubsection{Select the calculation object}

In terms of calculating the energy consumption of the building, the whole building can be selected as the main body of energy consumption calculation, so that the overall energy consumption status of the building can be known, which is convenient for overall control of building energy saving; it is also possible to select a part of the building for the calculation, so that the energy consumption composition of a specific functional space can be known in detail, and with an analysis on the specific space, a more accurate energy strategy can be formulated.

\subsubsection{Determine the calculation time}

Due to the periodic fluctuation of meteorological conditions in a year, the external meteorological parameters will change in the different calculation time. Take cold area as an example, when winter is chosen as the calculation time, the outside air temperature is lower, usually the main energy consumption of the building is heating energy consumption then, but if summer is chosen for calculation, it's necessary to consider the energy consumption influence of air conditioning refrigeration.

4.3.3 Analysis of energy consumption composition and calculation of comprehensive energy consumption index

After the calculation object is selected, the study analyzes the energy composition of the object, generally considering energy consumption and energy acquisition. The energy consumption mainly results from heating, cooling and lighting, while the energy acquisition is mainly from solar energy. The energy consumption and energy acquisition are calculated by superposition to obtain comprehensive energy consumption. As the reading space of the library, the main energy consumption in winter includes heating energy consumption index $E_{h}$ and lighting energy consumption index $E_{L}$, while the obtained energy is mainly solar energy $E_{S}$. The comprehensive energy consumption index $\mathrm{E}$, as $\mathrm{Eq}(5)$ :

$E=E_{L}+E_{h}-E_{s}$

4.3.4 Analyze the energy consumption factors and find the optimal energy consumption plan

The change of energy consumption is analyzed by adjusting the factors affecting energy consumption, such as building shape and window opening area. At the same time, the optimal energy consumption scheme is obtained through comprehensive analysis of daylighting condition and heating condition.

\section{ANALYSIS OF DAYLIGHTING DESIGN OF LIBRARY READING SPACE AND RELATED ENERGY CHARACTERISTICS}

\subsection{Project information}

The new Hebei Agricultural University Library explores the strategy of green ecological university library and is devoted to realizing humanistic environmental protection and ecological energy saving and providing better reading environment and library space for the teachers and students of Hebei Agricultural University. The new library building has 
eight floors above ground and one floor under ground, with a total depth of $62 \mathrm{~m}$, a total width of $170 \mathrm{~m}$, a total height of $41 \mathrm{~m}$ and a building area of $78,010 \mathrm{~m}^{2}$. In the library, a full open reading space is provided with 5 reading rooms, which have a total reading space area of about $2,500 \mathrm{~m}^{2}$. The plane of the main reading room is shown in Figure 3.

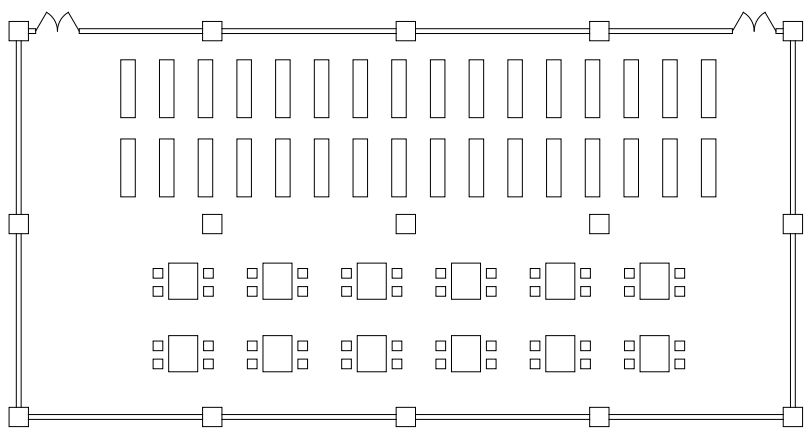

Figure 3. Reading room plan

\subsection{Analysis of daylighting in the reading space}

The library is designed with reinforced concrete frame shear wall structure, with a main body of $8,000 \mathrm{~mm} \times 8,000 \mathrm{~mm}$ column net and a layer height of about $4,500 \mathrm{~mm}$, and the daylighting form is single-sided daylighting, with a design window platform height of $1 \mathrm{~m}$ and a window height of $2.7 \mathrm{~m}$. Limited by the layer height, the window height cannot be adjusted greatly. Therefore, the window width is designed as a main variable, and the window area can be changed by adjusting the window width.

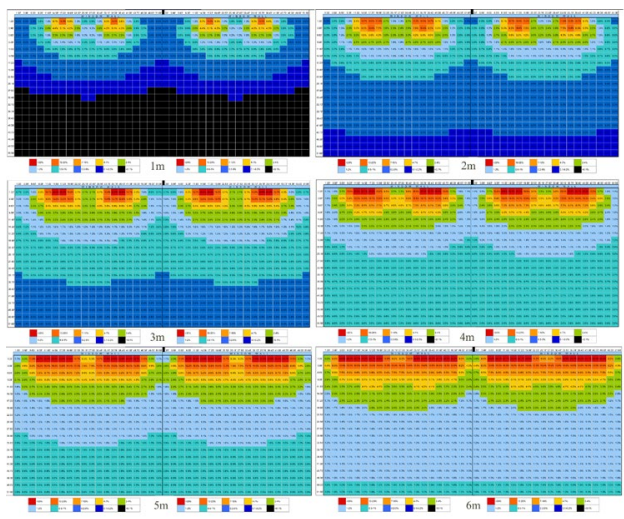

Figure 4. Distribution of daylight factors of the reading room with different window width

Taking the window width as a variable to simulate, Figure 4 is obtained. It can be seen from the figure that when the window width changes from $1 \mathrm{~m}$ to $6 \mathrm{~m}$, the daylighting factor of the reading room, increases obviously in the depth direction and the indoor uniformity increases gradually.

Then the daylighting factor in the depth direction is analyzed to get Figure 5. It can be seen that the daylighting factor increases from 0.15 to 0.25 at the window with the increase of the window width, the attenuation of the daylighting factor is more serious near the window, and the declining trend of the daylighting factor is not obvious after $4 \mathrm{~m}$. But with a lower daylighting factor, the influence of the window width on the daylighting factor is weak.

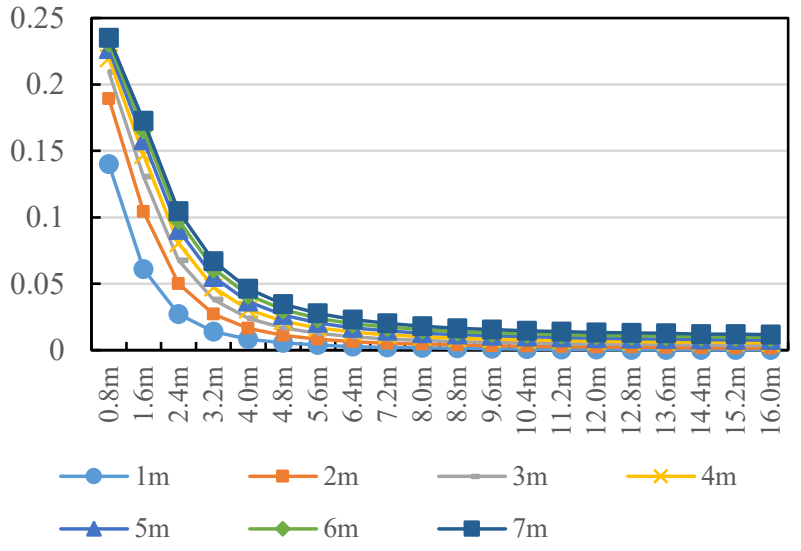

Figure 5. Analysis of daylighting factor in depth direction

According to the analysis of indoor lighting power, as in Figure 6 , it is found that with the increase of window width, the average lighting power demand decreases from $2,473 \mathrm{~W}$ to $1,254 \mathrm{~W}$, down by $49.29 \%$. Since the natural lighting alone cannot satisfy the illumination requirement completely, it is necessary to supplement the lighting. With the increase of window width, the lighting supplement power falls gradually from $4,082 \mathrm{~W}$ to $1,097 \mathrm{~W}$, down by $73.12 \%$. It is obvious that the increase of window width is very beneficial to the lighting energy saving.

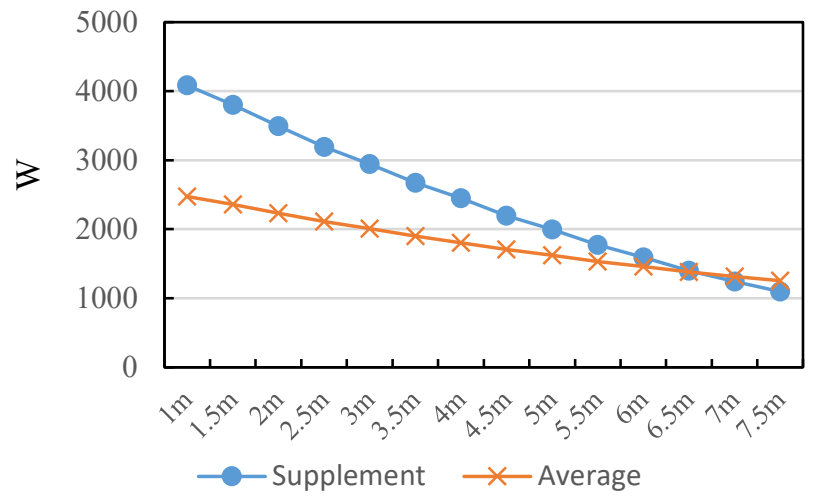

Figure 6. Analysis of indoor lighting power

\subsection{Analysis of hourly energy characteristics of enclosure structure of the reading space}

The hour-by-hour energy analysis of the reading space of the library before winter solstice as shown in Figure 7 indicates that the energy consumption of the reading space mainly includes the heat dissipation of walls and windows and the solar radiation from the windows into the room. It can be seen from the figure that the three energies are harmonic, and solar heat can be used as a supplement to heat dissipation, when the solar radiation intensity is higher and the window heat transfer coefficient is lower, the window becomes the heat component, and the size of the window area will determine how much heat gained, and also determine the amount of artificial lighting supplement. 


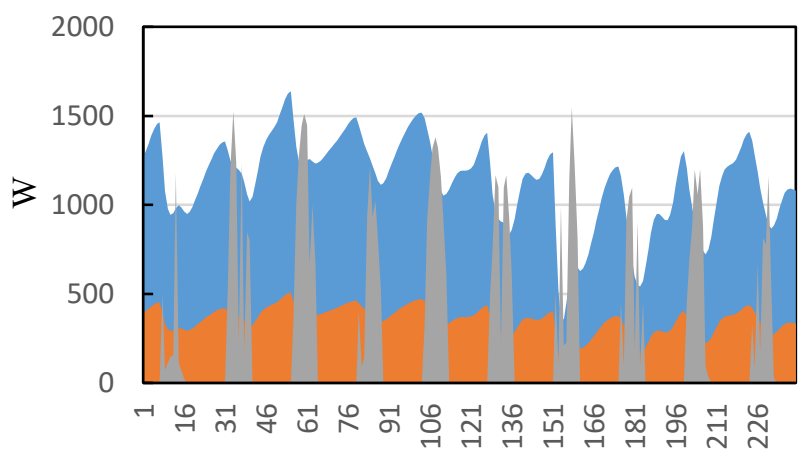

- Wall heat consumption

- Window heat consumption

Window heat

Figure 7. Hourly energy consumption of enclosure structure before and after the winter solstice

\subsection{Coupling relationship between window area and energy}

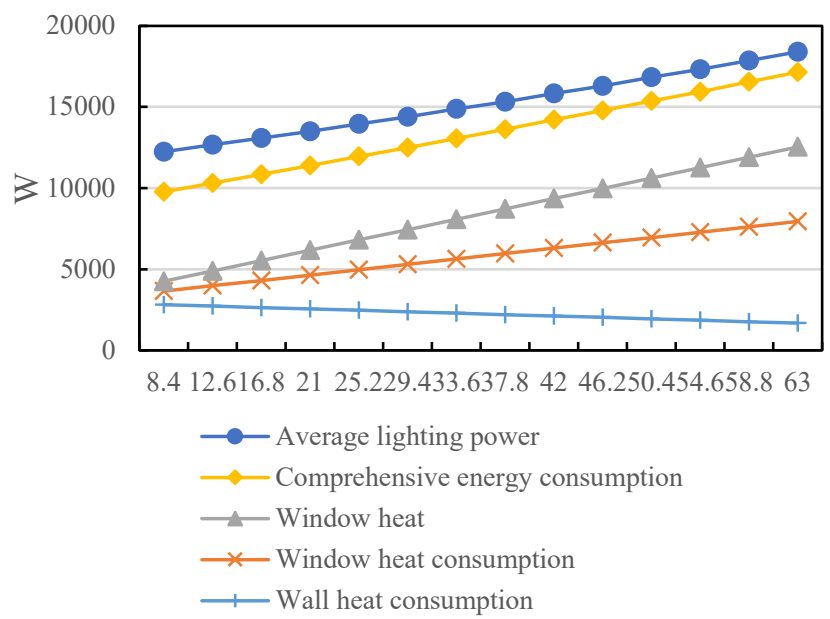

Figure 8. Curve of the relation between window area and energy consumption

Different energy consumption factors are simulated and analyzed to get Figure 8. It can be seen from the figure that with the increase of the window area, the wall heat consumption and the average lighting power decrease linearly, while the window heat consumption increases linearly, the solar energy obtained from the windows also increases linearly, and the overall energy consumption decreases slightly. When the window area increases from $8.4 \mathrm{~m} 2$ to $63 \mathrm{~m} 2$, the comprehensive energy consumption decreases from $5,058 \mathrm{~W}$ to $4,614 \mathrm{~W}$, and the energy consumption level is decreased by $8.7 \%$. It can be seen from this case that increasing the window area is very beneficial to the overall energy consumption of the reading room oriented towards the south. This is very different from the energy consumption of ordinary buildings.

\section{CONCLUSIONS}

Because of unique spatial characteristics and technical requirements and different energy consumption composition, the reading space of the library needs to consider all kinds of energy conditions, including wall heat dissipation, window heat dissipation, window heat gain, natural daylighting for energy saving and artificial lighting supplement in the scheme design. Only with the comprehensive consideration of these factors and the combination of dynamic simulation and static calculation, we can get the optimal energy-saving plan for the real green energy-saving of the library buildings.

\section{ACKNOWLEDGMENT}

This work was supported by National Natural Science Foundation of China (Grant No. 51708394).

\section{REFERENCES}

[1] Wang BH, Guo JL, Zhu L, Sun Y, Shao Z. (2016). Daylighting design for reading space in university libraries based on numerical simulation and analysis. Building Energy Efficiency 44(8): 81-83. https://10.3969/j.issn.1673-7237.2016.08.021

[2] Wu HH, Wang LC. (2013). Study on energy saving of modern library building. The Library Journal of Shandong (5): 71-74.

[3] Qiao L. (2014). Analysis of reader behavior patterns in reading space of University Library. Lantai World (23): 131-132.

[4] Kilic DK, Hasirci D. (2011). Daylighting concepts for university libraries and their influences on users' satisfaction. Journal of Academic Librarianship 37(6): 471-479.

[5] Dong W, Luo RR. (2017). Light environment of reading space in University Library. Technology Outlook (09): 226. https://10.3969/j.issn.16728289.2017.09.198

[6] Li JY. (2017): Research on Illumination for Reading Room of Library of Chongqing University's A District. Lamp and lighting, (01):24-27.

[7] Li DHW, Lou S, Ghaffarianhoseini A, Alshaibani KA, Lam JC. (2017). A review of calculating procedures on daylight factor based metrics under various cie standard skies and obstructed environments. Building \& Environment 112: 29-44. https://doi.org/10.1016/j.buildenv.2016.11.019

[8] Rizal Y, Robandi I, Yuniarno EM. (2016). Daylight factor estimation based on data sampling using distance weighting. Energy Procedia 100: 54-64. https://doi.org/10.1016/j.egypro.2016.10.153

[9] Galatioto A, Beccali M. (2016). Aspects and issues of daylighting assessment: A review study. Renewable \& Sustainable Energy Reviews 66: 852-860. https://doi.org/10.1016/j.rser.2016.08.018

[10] Bünning F, Sangi R, Müller D. (2017). A modelica library for the agent-based control of building energy systems. Applied Energy 193: 52-59. https://doi.org/10.1016/j.apenergy.2017.01.053

[11] Amasyali K, El-Gohary N. (2016). Building lighting energy consumption prediction for supporting energy data analytics. Procedia Engineering 145: 511-517. https://doi.org/10.1016/j.proeng.2016.04.036

[12] Mahapatra PS, Chatterjee S, Mukhopadhyay A, Manna NK, Ghosh K. (2016). Proper orthogonal decomposition of thermally-induced flow structure in an enclosure with alternately active localized heat sources. International 
Journal of Heat \& Mass Transfer 94(3): 373-379. https://doi.org/10.1016/j.ijheatmasstransfer.2015.11.027

[13] Bădescu V. (1992). Calculation of direct solar radiation on tilted surfaces. Solar Energy 48(5): 321-323. https://doi.org/10.1016/0038-092X(92)90060-N

\section{NOMENCLATURE}

$\begin{array}{ll}\mathrm{A}_{0} & \text { building area, } \mathrm{m}^{2} \\ \mathrm{E} & \text { comprehensive energy consumption } \\ \mathrm{E}_{\mathrm{h}} & \text { heating energy consumption, } \mathrm{W} \\ \mathrm{E}_{\mathrm{L}} & \text { lighting energy consumption, } \mathrm{W} \\ \mathrm{E}_{\mathrm{S}} & \text { mainly solar energy, } \mathrm{W} \\ \mathrm{Fi} & \text { Area of the enclosure structure, } \mathrm{m}^{2} \\ \mathrm{I} & \text { Solar vertical radiation intensity, } \mathrm{W} \\ \mathrm{K}_{\mathrm{i}} & \text { heat transfer coefficient of enclosure } \\ & \text { structure } \mathrm{W} /\left(\mathrm{m}^{2} \cdot \mathrm{K}\right) \\ \mathrm{PLD} & \text { lighting power density value, } \mathrm{W} / \mathrm{m}^{2} \\ \mathrm{~S} & \text { building are, } \mathrm{m}^{2}\end{array}$

$\mathrm{Sc}$

$\mathrm{T}_{\text {day }}$

shading coefficient

total daylighting hours per day, $\mathrm{h}$

\section{Greek symbols}

$\alpha$

$\varepsilon_{\mathrm{i}}$

\section{Subscripts}

n

$t_{e}$

$t_{i}$
Indoor solar radiation absorption coefficient thermal expansion coefficient

date of calculatio

Average outdoor temperature in the heating period, ${ }^{\circ} \mathrm{C}$

Average indoor calculated temperature for all rooms, ${ }^{\circ} \mathrm{C}$ 